Syntax Literate : Jurnal Ilmiah Indonesia p-ISSN: 2541-0849 e-ISSN : 2548-1398

Vol. 5, No. 3 Maret 2020

\title{
PENGARUH TRAINING DAN DEVELOPMENT TERHADAP EMPLOYEE PERFORMANCE DI PT. PAI SUKABUMI (JX)
}

\author{
Mariati Tirta Wiyata dan Adita Ayustiana \\ Institut Manajemen Wiyata Indonesia (IMWI) Sukabumi \\ Email : mariati.tirtawiyata@imwi.ac.id dan aditaayustiana@gmail.com
}

\section{Abstract}

A good company is able to control over its employees, so that they can work according to their function. Therefore, the company must provide training and development programs to increase employees' performance. This study is intended to determine whether the training and development is a variable either partially or collectively to a positive and significant effect on employee performance at PT. PAI Sukabumi (JX). The hypothesis of this study includes H1: there is a positive and significant effect from training on employee performance, H2: there is a positive and significant development effect on employee performance and H3: there is a positive and significant effect of training and development on employee performance. This research was conducted using primary data method in the form of questionnaire, distributed to all employees directly involved with packaging, labeling, and quality at PT. PAI Sukabumi (JX) and this questionnaire was partaken by 80 participants.This questionnaire consists of 67 statements related to training, development and employee performance which those questions were then analyzed by using SPSS Software version 25. This study uses a validity and reliability test, using a classic assumption test consisting of normality, multicollinearity and heteroscedasticity, and also multiple regression analysis consisting hypothesis testing ( $t$ test and $F$ test). The results show that the training and development variables have a positive and significant influence on employee performance both partially and jointly. With reference to the research conducted, I hope to see the management in JX are able to provide training programs for employees.

Keywords : Training, Development, Employee Performance.

\begin{abstract}
Abstrak
Perusahaan yang baik dituntut untuk bisa mengelola karyawannya agar dapat bekerja sesuai dengan fungsinya. Maka daripada itu perusahaan menyediakan program pelatihan dan pengembangan yang dilakukan untuk meningkatkan kinerja karyawan agar karyawan dapat bekerja maksimal dalam melaksanakan tugas dan tanggung jawab sesuai dengan fungsinya. Penelitian ini bertujuan untuk mengetahui apakah variabel pelatihan dan pengembangan secara parsial maupun bersama-sama berpengaruh positif dan signifikan terhadap kinerja karyawan di PT. PAI Sukabumi (JX). Hipotesis dari penelitian ini antara lain H1 : terdapat pengaruh pelatihan yang positif dan signifikan terhadap kinerja karyawan, $\mathrm{H} 2$ : terdapat pengaruh pengembangan yang positif dan signifikan terhadap kinerja karyawan dan
\end{abstract}


$\mathrm{H} 3$ : terdapat pengaruh pelatihan dan pengembangan yang positif dan signifikan terhadap kinerja karyawan. Penelitian ini dilakukan menggunakan data primer dalam bentuk kuesioner yang disebarkan kepada seluruh karyawan yang terlibat langsung dengan pengepakan, label dan kualitas di PT. PAI Sukabumi (JX) yaitu sebanyak 80 orang. Kuesioner ini terdiri dari 67 pernyataan mengenai pelatihan, pengembangan dan kinerja karyawan yang kemudian hasilnya dianalisis menggunakan software SPSS versi 25. Penelitian ini menggunakan pengujian instrument uji validitas dan reliabilitas, menggunakan uji asumsi klasik yang terdiri dari normalitas, multikolinearitas dan heteroskedastisitas, dan juga analisis regresi berganda yang terdiri dari uji hipotesis (uji t dan uji F). Hasilnya menunjukkan bahwa pada variabel pelatihan dan pengembangan terdapat pengaruh yang positif dan signifikan terhadap kinerja karyawan baik secara parsial maupun secara bersama-sama. Dengan mengacu kepada penelitian yang dilakukan diharapkan pihak manajemen bisa mendukung program pelatihan yang dilakukan untuk karyawan.

Kata kunci : Pelatihan, Pengembangan, Kinerja Karyawan

\section{Pendahuluan}

Di zaman yang semakin modern ini persaingan antar perusahaan tidak dapat dihindari. Perusahaan mempunyai etika tersendiri yang lebih dikenal dengan sebutan etika Bisnis dalam mengatur kehidupan perusahaannya (Wahyudin, 2017). Perusahaan dituntut untuk bisa mengelola karyawannya agar dapat bekerja sesuai dengan fungsinya. Pendapat (Mangkunegara, 2009) manajemen kepegawaian dan sumber daya manusia sangat penting bagi perusahaan dalam mengelola, mengatur, dan memanfaatkan pegawai sehingga dapat berfungsi secara produktif untuk tercapainya tujuan perusahaan. Hal ini dapat ditinjau berdasarkan pada kinerja karyawan nya. Kinerja yang baik akan tercapai bila ada peningkatan kerja yang optimal dan mampu memaksimalkan potensi sumber daya manusia yang dimiliki. Salah satu upaya yang dilakukan oleh perusahaan untuk meningkatkan kinerja karyawan yaitu melalui pelatihan dan pengembangan.

Program pelatihan bertujuan untuk memaksimalkan kinerja karyawan yang dilakukan dalam upaya peningkatan produktivitas, keahlian, disiplin kerja, sikap, dan keterampilan karyawan. Sikula dalam (Hasibuan, 2005) menyatakan, pelatihan adalah suatu proses pendidikan jangka pendek dengan menggunakan prosedur yang sistematis dan terorganisir, sehingga karyawan operasional belajar pengetahuan teknik pengerjaan dan keahlian untuk tujuan tertentu. Pelatihan ini merupakan usaha dari pihak perusahaan untuk meningkatkan kinerja karyawan dengan meningkatkan keahlian dan pengetahuan yang dilakukan seefisien dan seefektif mungkin untuk dapat melaksanakan dan menyelesaikan tugas ataupun pekerjaannya dengan baik.

Sedangkan program pengembangan bertujuan untuk meningkatkan kinerja karyawan dan memberikan kesempatan promosi bagi karyawan tersebut. lebih luas dalam hal perbaikan dan peningkatan kemampuan individu untuk melakukan pekerjaan yang sesuai dengan kebutuhan karirnya. Penyataan (Hasibuan, 2005) pengembangan 
adalah suatu usaha untuk meningkatkan kemampuan teknis, teoritis, konseptual, dan moral karyawan sesuai dengan kebutuhan pekerjaan/jabatan melalui pendidikan dan latihan. Kesimpulannya pengembangan dilakukan untuk meningkatkan kemampuan sdm agar dapat bekerja secara efektif dan menghasilkan prestasi baru dalam lingkungan perusahaan sesuai dengan kebutuhan karirnya.

Kinerja karyawan adalah prestasi kerja yang sesungguhnya yang dicapai seseorang dalam melaksanakan tugas yang didasarkan pada kecekatan. (Hasibuan, 2005) kinerja adalah suatu hasil kerja yang dicapai seseorang dalam melaksanakan tugas-tugas yang dibebankan kepadanya yang didasarkan atas kecakapan, pengalaman dan kesungguhan serta waktu. Kesimpulannya kinerja karyawan adalah prestasi kerja sesungguhnya yang dicapai oleh karyawan dalam menyelesaikan tugas secara maksimal dan tepat waktu yang digunakan sebagai dasar dalam penilaian terhadap karyawan tersebut.

Penelitian sebelumnya menyatakan bahwa pelatihan dan pengembangan memiliki pengaruh terhadap kinerja karyawan. Menurut (SITAMA, 2019) variabel pelatihan dan pengembangan memiliki pengaruh positif terhadap kinerja karyawan. Sedangkan menurut (Jumawan \& Mora, 2018) variabel pelatihan dan pengembangan karir baik secara parsial maupun bersama-sama berpengaruh signifikan terhadap kinerja karyawan. Program pelatihan dan pengembangan akan memberikan rasa percaya diri dan juga pemahaman mengenai tujuan dari pekerjaan yang akan mereka lakukan. Sehingga mereka akan lebih mandiri, fokus dan mampu bekerja efektif dan efisien.

Penilaian kinerja karyawan yang telah mengikuti pelatihan dan pengembangan akan ditinjau berdasarkan pada tingkat pembatalan order yang dilakukan konsumen maupun buyer yang dipengaruhi oleh persentase keliru pengepakan. Keliru pengepakan ini dinilai berdasarkan kesesuaian packaging, labeling dan juga kualitas yang dihasilkan perusahaan dengan standar yang sudah diberikan oleh konsumen dan buyer. Respon konsumen dan buyer atas kinerja karyawan khususnya yang berhubungan dengan pengepakan, label dan kualitas ini akan dipantau langsung oleh departemen Bisnis Unit, QA, dan pimpinan dari produksi. Penilaian kinerja lainnya didasarkan pada pendapat departemen Bisnis Unit dan QA terhadap hasil kerja selama satu tahun terakhir. Kinerja satu tahun terakhir masih dinilai kurang memuaskan oleh departemen Bisnis Unit dan QA terlihat dari persentase PO pembatalan order yang melebihi target yang telah ditentukan perusahaan yaitu $1 \%$ setiap bulan dari jumlah total PO. Data Tabel 1 menggambarkan persentase pembatalan pesanan perusahaan selama satu tahun terakhir. 
Tabel 1

Data PO Pembatalan Pesanan

\begin{tabular}{ccccc}
\hline No & Bulan & Total Cancel & Total PO & Persentase \\
\hline 1 & Januari & $10 \mathrm{PO}$ & $675 \mathrm{PO}$ & $1.48 \%$ \\
2 & Februari & $25 \mathrm{PO}$ & $821 \mathrm{PO}$ & $3.05 \%$ \\
3 & Maret & $13 \mathrm{PO}$ & $960 \mathrm{PO}$ & $1.35 \%$ \\
4 & April & $16 \mathrm{PO}$ & $881 \mathrm{PO}$ & $1.82 \%$ \\
5 & Mei & $9 \mathrm{PO}$ & $942 \mathrm{PO}$ & $0.95 \%$ \\
6 & Juni & $21 \mathrm{PO}$ & $786 \mathrm{PO}$ & $2.67 \%$ \\
7 & Juli & $21 \mathrm{PO}$ & $845 \mathrm{PO}$ & $2.49 \%$ \\
8 & Agustus & $25 \mathrm{PO}$ & $961 \mathrm{PO}$ & $2.60 \%$ \\
9 & September & $33 \mathrm{PO}$ & $1023 \mathrm{PO}$ & $3.23 \%$ \\
10 & Oktober & $15 \mathrm{PO}$ & $798 \mathrm{PO}$ & $1.88 \%$ \\
11 & November & $23 \mathrm{PO}$ & $952 \mathrm{PO}$ & $2.42 \%$ \\
12 & Desember & $20 \mathrm{PO}$ & $1121 \mathrm{PO}$ & $1.78 \%$ \\
\hline
\end{tabular}

Sumber : PT. PAI Sukabumi (JX), Bagian Marketing (2019)

Berdasarkan data di atas dapat dilihat bahwa pada satu tahun terakhir terdapat masalah pembatalan pesanandengan persentase di atas $1 \%$ kecuali untuk bulan Mei. Pembatalan pesananyang terjadi berawal dari banyaknya claim keliru pengepakan dan kualitas issue kepada departemen Bisnis Unit sebagai tanda ketidakpuasan konsumen dan buyer. Data tabel 2 menggambarkan claim keliru pengepakan dan kualitas issue yang terjadi di JX pada 1 tahun terakhir.

Tabel 2

Data CMPQI

\begin{tabular}{ccccc}
\hline No & Bulan & Total CMPQI & Total PO & Persentase \\
\hline 1 & Januari & $5 \mathrm{PO}$ & $675 \mathrm{PO}$ & $0.74 \%$ \\
2 & Februari & $3 \mathrm{PO}$ & $821 \mathrm{PO}$ & $0.37 \%$ \\
3 & Maret & $10 \mathrm{PO}$ & $960 \mathrm{PO}$ & $1,04 \%$ \\
4 & April & $6 \mathrm{PO}$ & $881 \mathrm{PO}$ & $0,68 \%$ \\
5 & Mei & $6 \mathrm{PO}$ & $942 \mathrm{PO}$ & $0,64 \%$ \\
6 & Juni & $9 \mathrm{PO}$ & $786 \mathrm{PO}$ & $1,45 \%$ \\
7 & Juli & $7 \mathrm{PO}$ & $845 \mathrm{PO}$ & $0,83 \%$ \\
8 & Agustus & $5 \mathrm{PO}$ & $961 \mathrm{PO}$ & $0,52 \%$ \\
9 & September & $9 \mathrm{PO}$ & $1023 \mathrm{PO}$ & $0,88 \%$ \\
10 & Oktober & $13 \mathrm{PO}$ & $798 \mathrm{PO}$ & $1,63 \%$ \\
11 & November & $13 \mathrm{PO}$ & $952 \mathrm{PO}$ & $1,37 \%$ \\
12 & Desember & $11 \mathrm{PO}$ & $1121 \mathrm{PO}$ & $0,98 \%$ \\
\hline
\end{tabular}

Sumber : PT. PAI Sukabumi (JX), Bagian Marketing (2019)

Kurang terampilnya karyawan dalam hal pengepakan, label dan kualitas menyebabkan claim dari konsumen dan buyer yang disampaikan langsung kepada departemen Bisnis Unit. Masalah claim keliru pengepakan dan kualitas issue yang 
terjadi di atas target yang ditentukan perusahaan yang setiap bulan dilaporkan kepada departemen Bisnis Unit mengenai adanya minyak pada sepatu, terdapat jarum di dalam sepatu, shape sepatu yang tidak konsisten, kesalahan pemasangan aksesoris, kesalahan penggunaan karton, tercampurnya aksesoris dalam satu karton maupun pesanan yang dikirim tanpa aksesoris masih terjadi dan di atas target yang ditetapkan.

Masalah keliru pengepakan dan kualitas yang dikeluhkan konsumen menjadi pusat perhatian top management JX. Kemampuan teknis karyawan mengenai perlakuan terhadap kebersihan sepatu, menjaga konsistensi sepatu, cara mengidentifikasi aksesoris yang dibutuhkan dan standar pemasangan aksesoris yang masih missing sehingga konsumen dan buyer tidak puas. Karyawan masih sering terlihat bingung ketika mengidentifikasi aksesoris yang akan digunakan maupun bagaimana cara memasang aksesoris yang baik dan benar sesuai dengan standar yang sudah ditentukan.

Kinerja yang rendah dari karyawan menjadikan dasar bagi pihak manajemen sumber daya manusia terutama divisi pelatihan dan pengembangan untuk mengambil tindakan untuk mengadakan program pelatihan tambahan atau program pengembangan lanjutan untuk meningkatkan kembali kinerja karyawan khususnya yang terlibat dengan pengepakan, label dan kualitas. Hasil penilaian kinerja dari pihak manajemen membantu karyawan dalam meningkatkan kinerja mereka. Program pelatihan dan pengembangan yang diadakan lebih lanjut diharapkan dapat mengubah cara kerja karyawan menuju keselarasan dalam mencapai tujuan organisasi.

Masalah keliru pengepakan dan kualitas yang dikeluhkan konsumen menjadi pusat perhatian top management JX. Masalah pembatalan pesanan yang melebihi standar yang telah ditetapkan di PT. PAI Sukabumi (JX) yang diduga karena faktor kurang terampilnya karyawan dalam mengidentifikasi kesesuaian aktual barang dengan standar yang ada. Penelitian ini akan menguji apakah terdapat pengaruh pelatihan dan pengembangan secara parsial maupun bersama-sama terhadap kinerja karyawan di PT PAI Sukabumi (JX).

\section{Metode Penelitian}

Metode penelitian adalah suatu penyelidikan yang bersifat sistematis agar dapat meningkatkan pengetahuan yang baik dan merupakan suatu upaya terorganisasi untuk menyelidiki suatu masalah tertentu yang membutuhkan jawaban. Penelian ini bersifat kuantitatif di mana data yang didapat dinyatakan dalam angka dan dianalisis dengan teknik statistik (Barker \& Tinnick, 2006) dengan mengunakan pendekatan asosiatif dan deskriptif.

Sampel adalah seluruh populasi, 80 karyawan yang terlibat langsung dengan pengepakan, label dan kualitas di PT. PAI Sukabumi (JX), Jawa Barat. Penelitian ini mengunakan analisis regresi berganda agar dapat mengetahui pengaruh variabel indipenden terhadap variabel dependen. (Zhang \& Riduan, 2011) menjelaskan regresi adalah suatu proses memperkirakan secara sistematis suatu hal yang paling mungkin terjadi berdasarkan informasi yang dimiliki pada masa lalu atau saat ini. 


\section{Hasil dan Pembahasan}

\section{Pengaruh Pelatihan terhadap Kinerja karyawan}

Pelatihan merupakan usaha dari pihak perusahaan untuk meningkatkan kinerja karyawan dengan meningkatkan keahlian dan pengetahuan yang dilakukan seefisien dan seefektif mungkin untuk dapat melaksanakan dan menyelesaikan tugas ataupun pekerjaannya dengan baik.

Dari hasil analisis deskriptif ada satu pernyataan yaitu sasaran yang jelas dengan skor 310. Pelatihan diadakan karena ada tujuan tertentu yang ingin dicapai oleh pihak yang menyelenggarakannya. Maka dari pada itu suatu pelatihan haruslah memiliki sasaran dan sasaran ini harus diperjelas sehingga hasilnya akan sesuai dengan apa yang diharapkan oleh pihak perusahaan atau manajemen.

Penelitian menunjukkan hasil bahwa pelatihan berpengaruh positif dan signifikan terhadap kinerja karyawan sehingga PT. PAI Sukabumi (JX). Pernyataan tersebut didukung oleh hasil regresi uji t variabel pelatihan (X1) dengan nilai $t$ hitung lebih besar dari pada nilai t tabel $2.316>1.994$ tingkat signifikan di atas 0,05 yaitu sebesar $0.023<0,05$. Pelatihan yang diselenggarakan di PT. PAI Sukabumi (JX) hanya dilakukan 1 kali dalam 3 bulan yang artinya pelatihan ini sangat jarang dilakukan dan memungkinkan para peserta lupa mengenai materi yang disampaikan pada saat pelatihan. Selain daripada itu ketika ada update dari konsumen ataupun buyer ada kemungkinan infonya tidak tersampaikan dengan baik dan tidak semuanya mengerti dan paham dengan update tersebut. Jadi jika pihak manajemen menginginkan hasil yang maksimal, alangkah lebih baik jika manajemen meninjau ulang sistem pelatihan ini.

\section{Pengaruh Pengembangan terhadap Kinerja karyawan}

Pengembangan dilakukan untuk meningkatkan kemampuan sumber daya manusia agar dapat bekerja secara efektif dan menghasilkan prestasi baru dalam lingkungan perusahaan sesuai dengan kebutuhan karirnya. Pengembangan juga dilakukan dengan tujuan memperbaiki efektifitas kerja karyawan dalam upaya mencapai target yang ditentukan perusahaan. Caranya dengan memperbaiki pengetahuan, keterampilan maupun sikap karyawan itu sendiri terhadap tugas yang diberikan kepada mereka.

Dari hasil analisis deskriptif ada beberapa pernyataan yaitu tingkat kerusakan dengan skor 310, tingkat kecelakaan dengan skor 309, tingkat pemborosan dengan skor 314, sasaran yang jelas dengan skor 312, 310 dan juga kepemimpinan dengan skor 311 yang rata-rata skornya $<315$. Kelima indikator pengembangan ini kurang jelas maka tujuan dan manfaat dari pengembangan tersebut tidak akan maksimal. Terutama dalam hal sasaran yang jelas karena pada variabel pelatihan pun skor yang didapat <315. Sasaran inilah yang nantinya akan menentukan hasil dari kinerja karyawan nantinya, jika sasarannya kurang tepat maka hasilnya pun akan kurang maksimal.

Penelitian menunjukkan hasil bahwa pengembangan berpengaruh positif dan signifikan terhadap kinerja karyawan. Semakin sering pengembangan dilakukan 
maka semakin tinggi tingkat kinerja karyawan, pernyataan tersebut didukung oleh hasil regresi uji $\mathrm{t}$ variabel pengembangan dengan nilai $\mathrm{t}$ hitung variabel pengembangan (X2) $4.955>1.994$ dengan tingkat signifikan di bawah 0.05 yaitu $0.000<0.05$. Pengembangan yang diselenggarakan di PT. PAI Sukabumi (JX) hanya dilakukan 1 kali dalam 6 bulan dan kuotanya hanya 1\% dari total karyawan di PT. PAI Sukabumi (JX) yang artinya kesempatan pengembangan yang dimiliki oleh PIC yang terlibat dalam pengepakan, label dan kualitas ini sangat kecil dan hal ini bisa membuat performance mereka turun. Selain daripada itu akan lebih baik jika manajemen bisa melakukan pengembangan dalam teknologinya juga. Jadi jika pihak manajemen menginginkan hasil yang maksimal, alangkah lebih baik jika manajemen meninjau ulang sistem pengembangan ini.

3. Pengaruh Pelatihan dan Pengembangan secara simultan terhadap Kinerja karyawan

Kinerja karyawan adalah prestasi kerja sesungguhnya yang dicapai oleh karyawan dalam menyelesaikan tugas secara maksimal dan tepat waktu yang digunakan sebagai dasar dalam penilaian terhadap karyawan tersebut. Penilaian kinerja (performance appraisal) sangat membantu memotivasi dan mengevaluasi karyawan agar dapat bekerja menyelesaikan tugas sesuai dengan standar yang diberikan.

Dari hasil analisis deskriptif terdapat dua pernyataan yaitu perbaikan dengan skor 305 dan juga perilaku dalam organisasi dengan skor 313 yang rata-rata skornya <315. Kedua indikator kinerja karyawan ini kurang memuaskan maka tujuan dan manfaat dari pelatihan dan pengembangan yang diadakan tersebut tidak akan maksimal. Jika perbaikan setelah diadakan pelatihan dan pengembangan kurang maksimal, maka harus ada perbaikan dalam hal pelatihan dan pengembangan yang diberikan atau ide lain yang dapat meningkatkan indikator ini. Sementara itu untuk pernyataan yang lain hanya perlu lebih ditingkatkan saja agar kinerja karyawan bisa lebih meningkat lagi.

Berdasarkan hasil penelitian yang telah dijelaskan di atas dapat disimpulkan bahwa pelatihan dan pengembangan berpengaruh positif dan signifikan terhadap kinerja karyawan. Maka dapat disimpulkan bahwa variabel pelatihan dan pengembangan secara bersama-sama mempengaruhi variabel kinerja karyawan sebesar $68.7 \%$. Hasil ini menunjukkan bahwa pelatihan dan pengembangan berpengaruh tinggi terhadap kinerja karyawan yang artinya ketika sistem pelatihan dan pengembangan di PT. PAI Sukabumi (JX) ini maksimal maka pihak manajemen akan diuntungkan dengan kinerja karyawan yang maksimal.

\section{Analisis Deskriptif Variabel}

Pada analisis deskriptif ini hasil jawaban kuesioner dari para responden dikategorikan menjadi 5 (lima) kategori yaitu Sangat Rendah (SR), Rendah (R), Sedang (S), Tinggi (T) dan Sangat Tinggi (ST). Skor terendah adalah 1 (nilai skor) $\mathrm{x}$ 80 responden $=80$ dan skor tertinggi adalah 5 (nilai skor) $\times 80$ responden $=400$. Jadi 
intervalnya adalah total range yaitu 320 (skor tertinggi - skor terendah) dibagi interval nilai skor yaitu 5 (jumlah nilai skor) hasilnya 64 .

Tabel 3

Data Pengkategorian

\begin{tabular}{lr}
\hline \multicolumn{1}{c}{ Kategori } & \multicolumn{1}{c}{ Skor } \\
\hline Sangat Rendah (SR) & $80-144$ \\
Rendah (R) & $144-208$ \\
Sedang (S) & $208-272$ \\
Tinggi (T) & $272-336$ \\
Sangat Tinggi (ST) & $337-400$ \\
\hline \multicolumn{2}{c}{ Sumber : Olah Data (2019) }
\end{tabular}

\section{a. Analisis Deskriptif Variabel Kinerja karyawan (Y)}

Dari hasil kuesioner yang telah disebar kepada seluruh sampel yang terlibat langsung dalam hal pengepakan, label dan kualitas di PT. Pratama Abadi Industri Sukabumi (JX) diketahui bahwa hasil dari pengkategorian variabel kinerja karyawan adalah tinggi. Jika diambil batas tengah dari kategori tinggi ini maka skor <315 merupakan batas tengahnya. Diantara semua pernyataan yang terdapat pada variabel kinerja karyawan ada dua pernyataan yaitu Y-10 (Perbaikan) dengan skor 305 dan juga Y-17 (Perilaku Dalam Organisasi) dengan skor 313. Pernyataan ini perlu ditinjau ulang oleh pihak manajemen PT. PAI Sukabumi (JX) karena jika kedua indikator kinerja karyawan ini kurang memuaskan maka tujuan dan manfaat dari pelatihan dan pengembangan yang diadakan tersebut tidak akan maksimal. Jika perbaikan setelah diadakan pelatihan dan pengembangan kurang maksimal, maka harus ada perbaikan dalam hal pelatihan dan pengembangan yang diberikan atau ide lain yang dapat meningkatkan indikator ini.

\section{b. Analisis Deskriptif Variabel Pelatihan (X1)}

Dari hasil kuesioner yang telah disebar kepada seluruh sampel yang terlibat langsung dalam hal pengepakan, label dan kualitas di PT. Pratama Abadi Industri Sukabumi (JX) diketahui bahwa hasil dari pengkategorian variabel pelatihan adalah tinggi. Jika diambil batas tengah dari kategori tinggi ini maka skor $<315$ merupakan batas tengahnya. Diantara semua pernyataan yang terdapat pada variabel pelatihan ada satu pernyataan yaitu X1-19 (Sasaran Yang Jelas) dengan skor 310 yang skornya <315. Pernyataan ini perlu ditinjau ulang oleh pihak manajemen PT. PAI Sukabumi (JX) karena jika sasaran pelatihan kurang jelas maka tujuan dan manfaat dari pelatihan tersebut tidak akan maksimal. Sasaran inilah yang nantinya akan menentukan hasil dari kinerja karyawan nantinya, jika sasarannya kurang tepat maka hasilnya pun akan kurang maksimal.

\section{c. Analisis Deskriptif Variabel Pengembangan (X2)}

Dari hasil kuesioner yang telah disebar kepada seluruh sampel yang terlibat langsung dalam hal pengepakan, label dan kualitas di PT. Pratama Abadi Industri Sukabumi (JX) diketahui bahwa hasil dari pengkategorian variabel 
pengembangan adalah tinggi. Jika diambil batas tengah dari kategori tinggi ini maka skor <315 merupakan batas tengahnya. Diantara semua pernyataan yang terdapat pada variabel pengembangan ada beberapa pernyataan yaitu X2-8 dan X2-9 (Tingkat Kerusakan) dengan skor 310, X2-11 (Tingkat Kecelakaan) dengan skor 309, X2-12, X2-13, X2-14 (Tingkat Pemborosan) dengan skor 314, 308, 314, X2-18, X2-19 (Sasaran Yang Jelas) dengan skor 312, 310 dan juga X2-24 (Kepemimpinan) dengan skor 311 yang rata-rata skornya <315. Pernyataan ini perlu ditinjau ulang oleh pihak manajemen PT. PAI Sukabumi (JX) karena jika kelima indikator pengembangan ini kurang jelas maka tujuan dan manfaat dari pengembangan tersebut tidak akan maksimal. Terutama dalam hal sasaran yang jelas karena pada variabel pelatihan pun skor yang didapat <315. Sasaran inilah yang nantinya akan menentukan hasil dari kinerja karyawan nantinya, jika sasarannya kurang tepat maka hasilnya pun akan kurang maksimal.

\section{Kesimpulan}

Hasil penelitian uji t menunjukkan bahwa terdapat pengaruh yang positif dan signifikan antara pelatihan terhadap kinerja karyawan di PT. PAI Sukabumi (JX). Hasil penelitian uji $\mathrm{t}$ menunjukkan bahwa terdapat pengaruh yang positif dan signifikan antara pengembangan terhadap kinerja karyawan. Hasil penelitian uji $\mathrm{F}$ juga menunjukkan bahwa terdapat pengaruh yang positif dan signifikan antara pelatihan dan pengembangan secara simultan terhadap kinerja karyawan.

Penelitian ini diharapkan dapat menambah wawasan dan pengetahuan terkait pelatihan dan pengembangan terhadap kinerja karyawan di PT. PAI Sukabumi (JX). Khususnya yang berminat untuk mengkaji lebih jauh dalam mengenai kinerja karyawan. Penulis juga berharap akan adanya penelitian lanjutan mengenai metode ini sehingga dapat dijadikan bahan rujukan bagi perusahaan untuk meningkatkan kinerja karyawan.

Penelitian ini juga memiliki keterbatasan dalam hal variabel yang digunakan. Variabel yang digunakan hanya pelatihan, pengembangan dan kinerja karyawan saja dan semua variabel diukur dengan kuesioner yang bersifat self-rating. Keterbatasan lainnya yaitu penelitian ini hanya fokus kepada sampel karyawan PT. PAI Sukabumi (JX) saja, sehingga tidak dapat digeneralisasi pada perusahaan lain.

Dengan mengacu kepada penelitian yang dilakukan diharapkan pihak manajemen bisa mendukung program pelatihan yang dilakukan untuk karyawan. Salah satu bentuk dukungan yang bisa diberikan adalah dengan memfasilitasi pelatihan dengan sarana dan prasarana yang baik, menyediakan instruktur yang kompeten di bidangnya, dan yang paling utama yaitu memperjelas sasaran yang ingin dicapai untuk semua program pelatihan terutama pelatihan pengepakan, label dan kualitas. 


\section{BIBLIOGRAFI}

Barker, David C., \& Tinnick, James D. (2006). Competing visions of parental roles and ideological constraint. American Political Science Review, 100(2), 249-263.

Hasibuan, Malayu S. P. (2005). Manajemen sumber daya manusia edisi revisi. Bumi Aksara, Jakarta, 288.

Jumawan, Jumawan, \& Mora, Martin Tanjung. (2018). Pengaruh Pelatihan Dan Pengembangan Karier Terhadap Kinerja Karyawan Perusahaan Korporasi. Jurnal Riset Manajemen Dan Bisnis (JRMB) Fakultas Ekonomi UNIAT, 3(3), 343-352.

Mangkunegara, A. Anwa. Prabu. (2009). Manajemen Sumber Daya Manusia Perusahaan. Bandung: Remaja Rosdakarya.

Sitama, Mega Fitria. (2019). Penilaian Harga, Pendapatan, Label Halal, Manfaat, Skala Prioritas, Persepsi Perasaan Boros Dan Keputusan Konsumen Dalam Pembelian Kosmetik Halal (Studi Kasus Mahasiswi Muslimah Fakultas Ekonomi Dan Bisnis Universitas Airlangga). Universitas Airlangga.

Wahyudin, Uyu. (2017). Peran Penting Pedoman Etika Bisnis Perusahaan Dalam Upaya Pencegahan Korupsi. Syntax Literate; Jurnal Ilmiah Indonesia, 2(12), 147-161.

Zhang, Yugen, \& Riduan, Siti Nurhanna. (2011). Catalytic hydrocarboxylation of alkenes and alkynes with CO2. Angewandte Chemie International Edition, 50(28), 6210-6212. 